\title{
The Practical Research for Enhancing the Capability of Scientific Research and Innovation of Graduated Students
}

\author{
Xiying Ma, Quanying Wu \\ School of Mathematics and Physics, Suzhou University of Science and Technology, Suzhou 215009, China \\ maxy@mail.usts.edu.cn,wqycyh@mail.usts.edu.cn
}

\begin{abstract}
The cultivation of scientific research and innovative ability is the core of postgraduate education. In this paper we presented some useful practical approaches for improving scientific research and innovative ability of graduated students. We build up the knowledge system of the students with innovative ability by means of setting up their courses and content of the courses. And the way of thinking of inventive and technology of the students is changed through some innovative programs and their thesis by consulting relevant documents, reading report, experimental designning and operating, data processing, paper writing and publication. Finally, the scientific research and innovative ability of the students will be further enhanced resulting from their independent thinking, strengthening the idea of innovation, focusing accumulation, generalization and summarization, sharing with and learn from team members, and relying on research practices.

Index Terms - graduated students, scientific research and innovation, enhancing the capability, practical research
\end{abstract}

\section{Introduction}

The cultivation of scientific research and innovative ability is the core of graduate education in colleges and universities. As we known that establishing an innovationoriented country must rely upon independent innovation. A country's innovation capacity relies on the quantity and quality of the creative talents of high quality. The real core technologies and key technologies can never buy by money. Graduate students are the future of creative talents, and the major force of building an innovation-oriented country. The innovative ability of them is affected directly the future and development of the future of a country and nation. Therefore, graduate education mainly taken on the important mission of training the creative talents of the students. For the specific countermeasure of raising the research and innovative ability, many scholars have engaged in a wide range of research [1-3]. In our university, we have made some try and efforts, and obtained some useful approaches. Through many years of practice, we found that it can be implemented mainly through four approaches. First, it needs a solid basis of knowledge systems and a broad base of knowledge, which is the root for cultivating innovative talents. Second, the scientific research and innovative thinking and ability are enhanced by continuously training through a series of a scientific research activities and graduate thesis. Third, students are encouraged to self-cultivation, to become the dominant roles of improving scientific research and innovative ability. The improving of scientific research and innovative ability of students is also an important supplement for teachers and graduate education, and plays an important role in the real practical education.

\section{Approaches and methods}

2.1 Optimize the course plan and the content, combined with the scientific research frontiers, to arouse student's interests

The postgraduate stage is a key stage for cultivation specialized technology and creative talent. First, the graduate students must have a broad basic theory and systemic expertise, and with an ability of independent study and expression. In setting of their courses, we tried to choose some courses that closely related to hot research points of today. For example, for optical engineering specialty, besides the traditional courses of physical optics and information optics, we selected 《Optoelectronic technology $》$, 《Photonic crystals》 and 《Guided wave optics》 courses. Specially, photonic crystals are a newly development subject in the 21 century. It will play a role of guiding and demonstration action for inspiring the innovation thinking of students, and stimulating their research interest and innovation thinking. On the content of courses, we made a large reform. Both the content of textbooks and the newest research results are taught. For instance, in chapter of silicon solar cell in 《Optoelectronic technology》, the contents of single crystal, polycrystals and amorphous silicon solar cells, included all kinds of thin film solar cell and organic cell, and their status and trends of solar cells are given. This makes the students easily find out the recent hot research points, and select their research direction of interest combined with their research fields.

\subsection{Paying attention to search research data materials, laying a good base for research work}

It needs searching a lot of data materials before and after the research projects, experiment data processing, and thesis writing in time and continuously, specially important for the former step. In fact, research works is just started from consulting information materials in domestic and foreign largely and systemically. It is said the experiment work have down a half if the documents are collected completely. It indicates the importance of looking up and processing information in the whole of research works. Graduate students in our school generally select their interest research project based on the programs of their instructors. Determining proper project, the students should obey a rule of from near to far in searching of the documents because the new research results usually included the previous research references, which make 
readers know of the current status and trends of the research. Students can look up documents in the researches area for recent 20 years, especially for the new development of recent years. The method of collecting date materials roughly read 15-20 papers, focusing on their abstract, introduction and construction, understanding the meaning and backdrop of the project, and making clear the reason the authors to carried out the research, finding out the research solution, method, and results. If the search work is behind determining a project that usually come from some problem in producing and experiments, or from the outstanding hard problems. In this case, the searching process must have strong points. First, it needs tracing back to the source and studying the history of the research. Then it needs to grasp the newest research results. The students can fully and detailed read some references appointed by their supervisor, make clear the technical route and what problems are not still solved in the work. Students should write period conclusion after finished each stage work that is base materials for their thesis. For instance, students must write "research review" after a search documents work, which are a notebook of study and a introduction stuff of the thesis.

\subsection{Participating the program of teachers, improving the scientific research and innovative ability}

The most effective means of cultivation scientific research and innovative ability of students are to join some scientific programs. Many graduate students come from a lot of subjects, and they are interdisciplinary candidates for take part in the entrance exams for postgraduate. Many students are self-taught the exam materials, the base of their subject is weak although they passed the exam. Therefore, for these interdisciplinary students, we should pay more attention to train their scientific research and innovative ability. We try to offer more opportunities for them for participating the scientific programs and academic activities. This process can be divided two steps: (1) training the scientific ability. It is a base. The research direction of students is determined by their instructor according the progress and needs of their programs. The students determine their research method, approach and technical route based on searching documents. Then the plan is supplied and perfected by their instructors. Next, the students systemically carry out the research work in all aspects instructed by the tutors. For example, synthesis some materials, the influence factors to optoelectronic properties of materials, such as temperature, pressure, and time etc, are determined firstly. For each factor, it needs systemically study then can obtain some rules. (2) Training the innovative ability. The innovative thinking and ability of students are cultivated based on the students with some research ability and integrated capability by using the studied knowledge. For instance, graphene is a hot research material at home and abroad recently. It is composed of a single carbon layer that has superior fast electron mobility, which can be used to make superior fast transistor. At the same time, graphene has strong optical transmission rate that can be used to make as transparency electrode for solar cell, LED devices, and panel display devices. We guided students to think other materials with same crystal structure, such as $\mathrm{MoS}_{2}, \mathrm{PbS}$ etc, whether have such properties or not. The students will open their thoughts and research method through compared these materials to graphene. After above steps of comparing and reasoning, the innovative thinking of students is enhanced, and finally arrived to the cultivating of the innovative ability.

\subsection{The self-cultivation of scientific research and innovative ability}

Today, there are many scientific programs of students offered by university, province, city and ministry of education in China, students can write applications to apply these project instructed by their tutors. Students can determine a research program based on above works and searching documents. And propose the research contents and objects, research plan and route after cooperated with their members. These steps are the process of self-cultivate for scientific research and innovative ability. It is an important change, the program previously offer by their supervise change to find it by themselves, they changes the role from passive to active. It is also a change of quantity to quality; realize the improvement of innovative ability.

\subsection{Date processing to thesis writing; realize sublimation} from practical to theory

The obtained experimental date is needed fully analyzed and processed. Compared with some existed theory, find out reasons and give some reasonable explanation for error. And find out the advancement and shortages as compare with some published papers, and give explanation foe the mechanism. This step is a key step for cultivating the scientific literacy and innovative ability of students. We found that a lot of students can complete the ordinary work of date processing, but can do nothing about some error or difference from theory or some published paper. They can not give the error reason or some reasonable explanation in term of they studied knowledge, even made some advantage date. Therefore, this step is an important students for comprehensive using they studied knowledge. Therefore, this step is very important for training innovative thinking of students. We found that the innovative thinking of students is significantly enhanced by guiding them analyzed and process datum using the studied knowledge.

\section{Summary}

We present some approach and method of raising graduate students' research and innovative competence. First, we construct the knowledge system of students with innovative ability by setting courses and courses content. Second, the research and innovative competence of students can be improved by scientific program and thesis of students through searching the documents, designing the experiments, datum processing, thesis writing and submission steps. Finally, it can be improved though independent thinking, addressing the innovative consciousness, paying attention to the accumulated 
and summarized, and focusing on the change and cooperation of the members.

\section{Acknowledgements}

The program is supported by the graduate student project of Suzhou University of Science and Technology (No. 091210006).

\section{Reference}

[1] Yezhong Zhou, Jiagang Hu, "Thinking of the flexible educational system of graduate students", Educational level and the graduate students education, vol. 1, pp. 3-7, March 2004.

[2] Yuqing Huang, "Cultivation of Innovative competence the graduate students", Chinese sientificinformation, vol. 14, pp. 251-252, 2009.

[3] Zhongwei Wang, Hemei Chen, "the courses innovative of the graduate students". Educational level and the graduate students education, vol. 9, pp. 14- 17, 2006. 